\title{
The Influence of the 1997 Updated Classification Criteria for Systemic Lupus Erythematosus: Epidemiology, Disease Presentation, and Patient Management
}

\author{
GRO ØSTLI EILERTSEN, ANDREA BECKER-MEROK, and JOHANNES C. NOSSENT
}

\begin{abstract}
Objective. The 1997 update of the American College of Rheumatology classification criteria (ACR97) for systemic lupus erythematosus (SLE) has not been validated. We determined to what extent their introduction influenced the epidemiology and clinical characteristics of the disease in northern Norway.

Methods. Annual incidence and point-prevalence rates, clinical manifestations, and outcome were determined in an inception cohort of patients with SLE in northern Norway, included between 1996 and 2006, using ACR97 criteria (97acr). These findings were compared with a cohort from the same area enrolled 1978-1995 using the 1982 revised criteria ACR82 (82acr).

Results. The mean annual incidence of SLE was 3.00 for cohort 97 acr $(n=58)$ versus 2.63 for cohort $82 \mathrm{acr}(\mathrm{n}=81)(\mathrm{p}=0.5)$. All patients in the 97acr cohort also fulfilled the 1982 criteria; however, significantly fewer patients presented with discoid rash [odds ratio (OR) 0.31)], arthritis (OR 0.24), renal (OR 0.28) or hematological disorder (OR 0.27 ), and significantly more with anti-dsDNA (OR 2.57) and antiphospholipid antibodies (OR 27.9). Initial treatment with intravenous pulse methylprednisolone (OR 9.23), azathioprine (OR 6.32), and low-dose aspirin (OR 20.9) was increased in cohort 97acr. Five- (95.2\%) and 10-year survival (91.9\%) rates were also improved for cohort 97acr. Conclusion. The ACR97 criteria set has construct validity compared to the ACR82 criteria set. SLE incidence remains unchanged in northern Norway, but a significant reduction of renal disease and further improvements in survival rates occurred simultaneously with increased serological surveillance with ELISA-based assays and early immunosuppressive and anticoagulant therapy. (J Rheumatol First Release Jan 15 2009; doi:10.3899/jrheum.080574)
\end{abstract}

Key Indexing Terms:

SYSTEMIC LUPUS ERYTHEMATOSUS

PATIENT CARE CLASSIFICATION CRITERIA

EPIDEMIOLOGY

DIAGNOSIS

Systemic lupus erythematosus (SLE) is one of the most common systemic autoimmune diseases, characterized by a highly variable clinical presentation and an unpredictable disease course ${ }^{1,2}$. There are considerable regional differences in the epidemiology of SLE, with the lowest incidence rates observed in Caucasian populations ${ }^{3-6}$. There has been a trend towards an increased incidence and prevalence of

From the Institute of Clinical Medicine, Department of Rheumatology, Medical School, University of Troms $\phi$; and the Department of

Rheumatology, University Hospital of Northern Norway, Troms $\phi$, Norway.

Supported by grants from Norske Kvinners Sanitetsforening (grant R2/06), Troms $\phi$, and Harstad Revmatikerforening.

G.Ø. Eilertsen, MD; A. Becker-Merok, MD, Institute of Clinical Medicine, Department of Rheumatology, Medical School, University of Troms $\phi$;

J.C. Nossent, MD, Professor, Institute of Clinical Medicine, Department of Rheumatology, Medical School, University of Troms $\phi$ and Department of Rheumatology, University Hospital of Northern Norway.

Address reprint requests to Dr. G. $\varnothing$. Eilertsen, Institute of Clinical Medicine, Department of Rheumatology, Medical School, University of Troms $\phi$, 9037 Troms $\phi$, Norway. E-mail: gro.ostli.eilertsen@unn.no

Accepted for publication October 8, 2008.
SLE for Caucasian cohorts in the USA ${ }^{7-9}$, while the incidence has been stable in southern Sweden ${ }^{10}$.

The 1982 revised criteria for the classification of SLE by the American College of Rheumatology (ACR) were modified in $1997^{11,12}$, where the presence of LE cells was replaced with the presence of antiphospholipid antibodies (aPL). These recommendations reflected that few laboratories were still performing the LE cell assay. The recommendations for the 1997 update were consensus-based and the operating characteristics of the updated criteria set have never been validated. As persistent aPL can also be found in many other conditions ${ }^{13-16}$, the inclusion of aPL in ACR97 could, in theory, change SLE incidence and prevalence, e.g., by including patients with undifferentiated connective tissue disease or antiphospholipid syndrome (APS). In the same way, the association between aPL and thrombosis ${ }^{16,17}$ may affect the spectrum of disease manifestations by emphasizing vascular events in SLE. While the prognosis for patients with SLE has improved over time and standardized mortali- 
ty rates (SMR) have decreased in Caucasian SLE cohorts, mortality in patients with SLE remains higher than in matched controls with cardiovascular events as a major cause of death ${ }^{7,18,19}$. Our study compared the epidemiological and clinical characteristics of a recent SLE inception cohort defined by the 1997 update of the classification criteria of SLE (ACR97) with an existing cohort from the same region classified according to the 1982 revised ACR criteria (ACR82), where one criterion is presence of LE cells as opposed to ACR97.

\section{MATERIALS AND METHODS}

The catchments area for our study consisted of the 2 northernmost counties of Norway (population in 1993 was 224,724 inhabitants, population on January 1, 2007, 226,898) representing 5\% of the Norwegian population (Statistics Norway; www.ssb.no). The Department of Rheumatology at University Hospital of Northern Norway is the only rheumatology center in this area, which otherwise has 3 local hospitals and no privately practicing rheumatologists. Data sources were hospital patient registries (inand outpatients) for all departments in these 4 hospitals. Patients were identified through computerized diagnostic registry searches for International Classification of Diseases-10 codes for SLE (M32.0, M32.1, M32.8, and M32.9), Sjögren's syndrome (M35.0), unclassified connective tissue disease (M35.9), and discoid lupus (L93.0). All adult patients (16 yrs or older) who fulfilled 4 or more of the ACR $97^{12}$ criteria in the 11-year period prior to January 1, 2007, were included and designated cohort 97acr. Children with SLE were registered separately and included in prevalence data when reaching 16 years of age (during the study period). Cohort $82 \mathrm{acr}$ is a previously reported cohort of SLE incident cases defined by ACR82 during 1978-95 ${ }^{11}$, constituted in the same area and manner with a high case ascertainment ${ }^{5}$. Demographic data, clinical data, disease activity by SLE Disease Activity Index (SLEDAI) and Systemic Lupus International Collaborating Clinics/ACR Damage Index (SLICC/ACR DI) were collected by a single investigator and stored in a central database as described ${ }^{5}$. Missing data were considered to indicate negative findings. Scoring of both SLEDAI and SLICC/ACR DI have been validated ${ }^{20,21}$.

Antinuclear antibody (ANA) screening was performed at a single clinical immunology department by immunofluorescence techniques until 1994 and by automated ELISA since then. All ANA-positive sera were routinely tested for the presence of antibodies (Ab) against double-stranded DNA (anti-dsDNA) by Crithidia luciliae immunofluorescence assay and ELISA (since 1995), as well as antibodies against Ro (anti-SSA), La (anti-SSB), Smith (anti-Sm), and anti-U1 small nuclear ribonucleoparticle (anti-U1-snRNP), all by ELISA techniques. Both IgG and IgM isotypes of anticardiolipin (aCL) antibodies were tested by commercial ELISA kits since 1992 (cutoff levels for positive findings > 16 IU), while lupus anticoagulant (LAC) was tested in a phospholipid-dependent coagulation $\operatorname{assay}^{22}$.

Data reported are median values unless indicated otherwise. Continuous data were analyzed by Mann-Whitney U-test, Poisson distribution contingency tables, or Fisher's exact test in case of low numbers. Annual incidence rate (AIR) and point-prevalence (PP) are reported per 100,000. Survival rates were estimated by Kaplan-Meier method and compared by log-rank testing. Standardized mortality rates were calculated by randomly assigning each patient 5 controls, born in the same year and month and matched for sex and municipality identified by area code. The prognostic values of potential survival predictors were analyzed by Cox proportional hazards models. Hazard ratios (HR) are reported with $95 \%$ confidence interval (95\% CI). All statistical analyses were performed with SPSS 11.0 and Epi-Info 4.1. The regional ethics board approved the study protocol and all patients gave written informed consent for the identified use of their data.

\section{RESULTS}

Incidence data. Inception cohort 97acr contained 58 patients with new-onset SLE and was similar to cohort 82acr with regard to age (39.4 vs $41.7 \mathrm{yrs} ; \mathrm{p}=0.6)$, sex $(84.5 \%$ vs $85.2 \%$ female; $\mathrm{p}=0.4)$, and ethnicity $(1.7 \%$ vs $1.2 \%$ nonCaucasian; $\mathrm{p}=0.8$ ). The estimated average AIR was 2.8 (95\% CI 2.2-3.3) for the whole study period (1978-2006), with no significant difference between the AIR for cohort 97acr $(3.00,95 \%$ CI 2.0-4.0) and cohort 82acr $(2.63,95 \%$ CI 1.9-3.7) ( $\mathrm{p}=0.5$; Table 1). The overall AIR was highest among women $30-49$ years of age in both cohorts (8.27 vs 5.79; $\mathrm{p}=0.093$; Table 1).

Prevalence data. As 16 patients migrated and 40 patients died during the whole study period they were excluded from prevalence analysis. Another 19 patients with SLE diagnosed before 1978 and 12 pediatric patients reaching 16 years of age during the observation period were included in the prevalence data for a total number of 114 adult patients. The crude point-prevalence at January 1, 2007, was 64.1 overall, 108.6 for women, and 20.0 for men per 100,000 (Figure 1). The disease prevalence increased gradually during the observation period, with the highest point-prevalence at 124.9 seen in women age 50 years or older (data not shown).

Clinical and laboratory manifestations. The time between onsets of the first SLE-related symptom and fulfilment of ACR criteria was 1 year in both cohorts, regardless of age and sex (data not shown). The mean number of classification criteria in cohort 97 acr was significantly lower than in cohort 82acr [4.6 (range 4-7) vs 6.0 (range 4-9); p < 0.001]. In cohort 97acr, aPL antibodies occurred simultaneously with anti-dsDNA or anti-Sm antibodies in $93.3 \%$ at diagnosis; in $6.7 \%$ aPL presence was the only immunological criterion, but these patients fulfilled at least 4 other criteria at diagnosis. Overall, all patients in the 97acr cohort fulfilled at least 4 of the ACR82 criteria, even though the assay for LE cells was not available for the patients in this cohort. In cohort $82 \mathrm{acr}, 33 \%$ of the patients with SLE presented with positive LE cells, but only $6.2 \%$ as the fourth and only immunologic classification criterion. At diagnosis, SLEDAI scores were similar for both cohorts [8.3 (95\% CI 6.6-10.0) vs 8.8 (95\% CI 7.4-10.4); $\mathrm{p}=0.445$ ], but clinical features differed considerably (Table 2). In cohort 97acr significantly fewer presented with discoid rash (OR 0.31), arthritis (OR 0.24 ), proteinuria (OR 0.22), leukopenia (OR 0.35), or lymphopenia (OR 0.25). In contrast, the frequencies of antidsDNA antibodies and aPL antibodies were significant increased in cohort 97acr (OR 2.57 and 20.9, respectively), while no significant increase was seen for other autoantibodies such as anti-SSA (33\% vs 20\%), anti-SSB (10\% vs $7 \%)$, rheumatoid factor (12\% vs $17 \%)$, or anti-U1-snRNP (12\% vs $9 \%$ ) (data not shown).

To explore this increase in serological classification criteria further, we also compared the intensity of serological 
Table 1. Mean annual incidence rates (AIR) for SLE per 100,000 at risk by age and sex, comparison between 2 cohorts in northern Norway. Patients in 97 acr cohort were classified by ACR97, while ACR82 was used in 82acr cohort.

\begin{tabular}{|c|c|c|c|c|c|c|c|c|}
\hline & \multirow[t]{2}{*}{ Population } & \multicolumn{2}{|c|}{$\begin{array}{c}\text { 97acr Cohort, } \\
\text { 1996-2006 }\end{array}$} & \multicolumn{2}{|c|}{$\begin{array}{c}\text { 82acr Cohort, } \\
\text { 1978-1995 }\end{array}$} & \multirow[t]{2}{*}{$\begin{array}{c}\text { 97acr vs 82acr, } \\
\text { p }\end{array}$} & \multicolumn{2}{|c|}{$\begin{array}{l}\text { Whole Period } \\
\text { 1978-2006 }\end{array}$} \\
\hline & & $\mathrm{n}$ & $\operatorname{AIR}(95 \% \mathrm{CI})$ & $\mathrm{n}$ & AIR (955 CI) & & $\mathrm{n}$ & $\operatorname{AIR}(95 \% \mathrm{CI})$ \\
\hline Adults & 177,640 & 58 & $3.0(2.0-4.0)$ & 81 & $2.6(1.9-3.7)$ & 0.500 & 139 & $2.8(2.2-3.3)$ \\
\hline Men & 89,952 & 9 & $0.9(0.0-1.8)$ & 12 & $0.8(0.4-1.1)$ & 0.738 & 21 & $0.8(0.4-1.2)$ \\
\hline Women & 87,688 & 49 & $5.1(3.7-6.4)$ & 69 & $4.6(3.1-6.1)$ & 0.208 & 118 & $4.8(3.7-5.8)$ \\
\hline $30-49$ & 30,798 & 28 & $8.3(5.4-1.1)$ & 31 & $5.8(3.2-8.4)$ & 0.093 & 59 & $6.7(4.9-8.6)$ \\
\hline Over 50 & 31,712 & 9 & $2.6(0.7-4.4)$ & 18 & $3.2(1.3-5.0)$ & 0.848 & 27 & $2.9(1.7-4.2)$ \\
\hline
\end{tabular}

Total number in population in 1993 was 224,724 inhabitants. Children: < 16 yrs; ACR: American College of Rheumatology; ACR97: 1997 update of criteria for systemic lupus erythematosus (SLE); ACR82: 1982 revised criteria. $n$ : number of incident cases during the period.

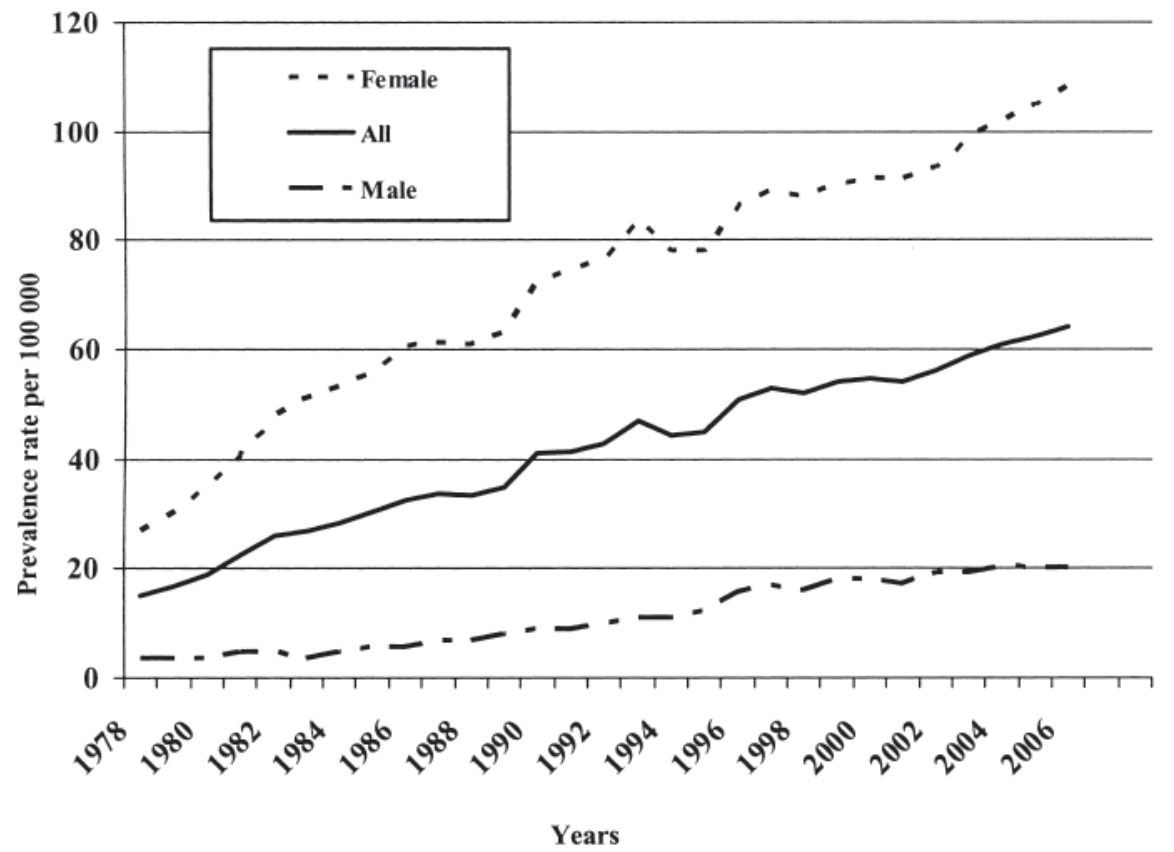

Figure 1. Prevalence rates of SLE in Northern Norway, 1978-2006.

surveillance. With the exception of ANA-negative patients, all patients in both cohorts were surveyed for anti-dsDNA $\mathrm{Ab}(98 \%$ vs $99 \%$; $\mathrm{p}=0.9)$. The annual number of antidsDNA assays performed was significantly higher in the 97acr cohort (2.32 vs $1.34 ; \mathrm{p}<0.001)$. As the assay for $\mathrm{aCL}$ antibodies was introduced in 1992, the data of aPL profiles at diagnosis were biased. When including all available data on the ever-presence of aPL, there was a slight, although not statistically significant, increase in the number of aPL-positive patients in the 97acr cohort (41\% vs $31 \%$; $p=0.201$ ), possibly because more 97 acr patients were ever tested for aPL (97\% vs $83 \%$; $=0.014)$. The increase in the annual numbers of aPL tests performed in cohort $97 \mathrm{acr}$ (2.3 vs 1.4; $\mathrm{p}<0.001)$ was similar to that for anti-dsDNA testing.
Disease course. Initial treatment: During the first 4 months of disease there was increased use of azathioprine $(\mathrm{p}=$ $0.011)$, intravenous pulse methylprednisolone $(\mathrm{p}=0.015)$, and low-dose aspirin ( $\mathrm{p}<0.001$ ) in cohort 97acr (Table 2). The number of patients treated with nonsteroidal antiinflammatory drugs, hydroxychloroquine, cyclophosphamide, methotrexate, cyclosporine A, plasmapheresis, oral corticosteroids, warfarin, or antihypertensive drugs showed no significant differences (data not shown).

Mortality: At the end of the observation period, 5 women in cohort $97 \mathrm{acr}$ had died, for a case fatality rate of $8.6 \%$. At death, disease duration was 19 months (range 3-77) and age 50 years (range 19-75). The overall adjusted SMR was highest in cohort 97acr: overall 3.00 versus 1.88 and women 
Table 2. SLE manifestations at diagnosis. Treatment during the first 4 months after diagnosis.

\begin{tabular}{lcccc}
\hline Criteria & $\begin{array}{c}\text { 97acr Cohort, } \\
\mathrm{n}=58(\%)\end{array}$ & $\begin{array}{c}82 \mathrm{acr} \text { Cohort, } \\
\mathrm{n}=81(\%)\end{array}$ & OR & $95 \% \mathrm{CI}$ \\
\hline Malar rash & $35(60)$ & $43(53)$ & 1.35 & $0.7-2.7$ \\
Discoid rash & $18(31)$ & $48(59)$ & 0.31 & $0.2-0.6$ \\
Photosensitivity & $30(52)$ & $53(65)$ & 0.57 & $0.3-1.1$ \\
Oral ulcers & $12(21)$ & $25(31)$ & 0.58 & $0.3-1.3$ \\
Arthritis & $31(54)$ & $67(83)$ & 0.24 & $0.1-0.5$ \\
Serositis & $11(19)$ & $21(26)$ & 0.67 & $0.3-1.5$ \\
Renal disorder & $7(12)$ & $27(33)$ & 0.28 & $0.1-0.7$ \\
Proteinuria & $5(9)$ & $24(31)$ & 0.22 & $0.1-0.6$ \\
Casts & $6(10)$ & $16(20)$ & 0.47 & $0.2-1.3$ \\
Neurological disorder & $1(2)$ & $5(5)$ & 0.27 & $0.0-2.4$ \\
Hematological disorder & $27(47)$ & $62(77)$ & 0.27 & $0.1-0.6$ \\
Leukopenia & $16(28)$ & $42(52)$ & 0.35 & $0.2-0.7$ \\
Lymphopenia & $15(26)$ & $47(58)$ & 0.25 & $0.1-0.5$ \\
Immunological disorder & $43(74)$ & $57(70)$ & 1.21 & $0.6-2.8$ \\
LE cells & $0(0)$ & $27(33)$ & - & - \\
Anti-DNA antibodies & $39(67)$ & $36(44)$ & 2.57 & $1.3-5.2$ \\
Anti-Sm antibodies & $6(10)$ & $8(10)$ & 1.05 & $0.4-3.2$ \\
False-positive syphilis test & $5(9)$ & $7(9)$ & 1.00 & $0.3-3.3$ \\
aPL & $15(26)$ & $1(1)$ & 27.9 & $3.6-218$ \\
Antinuclear antibodies & $53(95)$ & $78(96)$ & 0.41 & $0.1-1.8$ \\
Azathioprine & $8(14)$ & $2(3)$ & 6.32 & $1.3-31.0$ \\
Methylprednisolone & $6(10)$ & $1(1)$ & 9.23 & $1.1-78.9$ \\
Low-dose aspirin & $12(21)$ & $0(0)$ & 20.9 & $2.6-165.7$ \\
\hline
\end{tabular}

For abbreviations see Table 1.

3.75 versus 1.94 (Table 3). In cohort 82acr, 25 patients had died (case fatality rate $30.9 \%$ ) after longer disease duration (98 months, range 1-209) and at higher age (66 yrs, range 19-81) than in cohort 97acr.

Survival: Ten-year survival for patients with SLE was significantly lower than in the general population $(\mathrm{p}=0.004$ for cohort 97acr, and $\mathrm{p}<0.001$ for cohort 82acr). Five- and 10-year survival estimates were higher in cohort $97 \mathrm{acr}$ (95.2\% and $91.9 \%$, respectively) than in cohort 82acr (90.8\% and $80.5 \%$ ), but this increase was not statistically significant (Figure 2).

Cox proportional hazard models identified potential pre- dictors of survival within 10 years of diagnosis $(p<0.1$ to enter, $\mathrm{p}<0.05$ to stay). In cohort 97acr, the initial presence of renal disease (HR 10.9; $\mathrm{p}=0.009$ ), initial treatment with pulse methylprednisolone (HR 1.5; p = 0.012 ), low-dose aspirin (HR 1.3; p = 0.005), and antihypertensive drugs (HR 1.3; $\mathrm{p}=0.001)$ were associated with poorer survival by univariate analysis. The low number of events did not allow multivariate analysis of the interdependency of these predictors. In cohort $82 \mathrm{acr}$, age $>50$ years at diagnosis was the sole independent predictor for poorer survival (HR 12.2; $\mathrm{p} \leq$ 0.001; Table 4).

Table 3. Sex and age-adjusted standardized mortality ratio (SMR) for the various SLE cohorts and controls (C).

\begin{tabular}{|c|c|c|c|c|c|c|c|c|c|c|c|c|}
\hline \multirow[b]{3}{*}{ Children } & \multicolumn{4}{|c|}{ 97acr Cohort, 1996-2006 } & \multicolumn{4}{|c|}{ 82acr Cohort, 1978-1995 } & \multicolumn{4}{|c|}{ Whole Period, 1978-2006 } \\
\hline & $\begin{array}{c}\text { SLE, } \\
\mathrm{n}=58 \\
\text { No. }\end{array}$ & $\begin{array}{l}\text { Control, } \\
\mathrm{n}=290 \\
\text { Peaths }\end{array}$ & SMR & $95 \% \mathrm{CI}$ & $\begin{array}{l}\text { SLE, } \\
\mathrm{n}=81 \\
\text { No }\end{array}$ & $\begin{array}{l}\text { Control, } \\
\mathrm{n}=405 \\
\text { Deaths }\end{array}$ & SMR & $95 \% \mathrm{CI}$ & $\begin{array}{c}\text { SLE, } \\
\mathrm{n}=139 \\
\text { No. } \mathrm{D}\end{array}$ & $\begin{array}{l}\text { Control, } \\
\mathrm{n}=695 \\
\text { eaths }\end{array}$ & SMR & $95 \% \mathrm{CI}$ \\
\hline & 0 & 0 & $\mathrm{NC}$ & - & 0 & 0 & $\mathrm{NC}$ & - & 0 & 0 & $\mathrm{NC}$ & - \\
\hline Adults & 5 & 5 & 3.00 & $1.6-5.8$ & 25 & 55 & 1.88 & $1.3-2.7$ & 30 & 60 & 2.00 & $1.4-2.8$ \\
\hline Men & 0 & 2 & $\mathrm{NC}$ & - & 5 & 13 & 1.67 & $0.7-4.1$ & 5 & 15 & 1.50 & $0.6-3.5$ \\
\hline $16-29$ & 1 & 0 & $\mathrm{NC}$ & - & 1 & 1 & 3.17 & $0.6-17.9$ & 2 & 1 & 4.06 & $1.6-10.5$ \\
\hline $30-49$ & 1 & 1 & 3.00 & $0.7-12.5$ & 4 & 4 & 2.72 & $1.3-5.9$ & 5 & 5 & 2.87 & $1.5-5.6$ \\
\hline $50-69$ & 2 & 2 & 3.04 & $1.0-9.2$ & 8 & 5 & 3.32 & $1.9-5.7$ & 10 & 7 & 3.28 & $2.0-5.3$ \\
\hline $70+$ & 1 & 1 & $\mathrm{NC}$ & - & 7 & 32 & 1.44 & $0.6-3.2$ & 8 & 32 & 1.54 & $0.7-3.3$ \\
\hline
\end{tabular}

NC: not calculated. Children $<16$ years. 


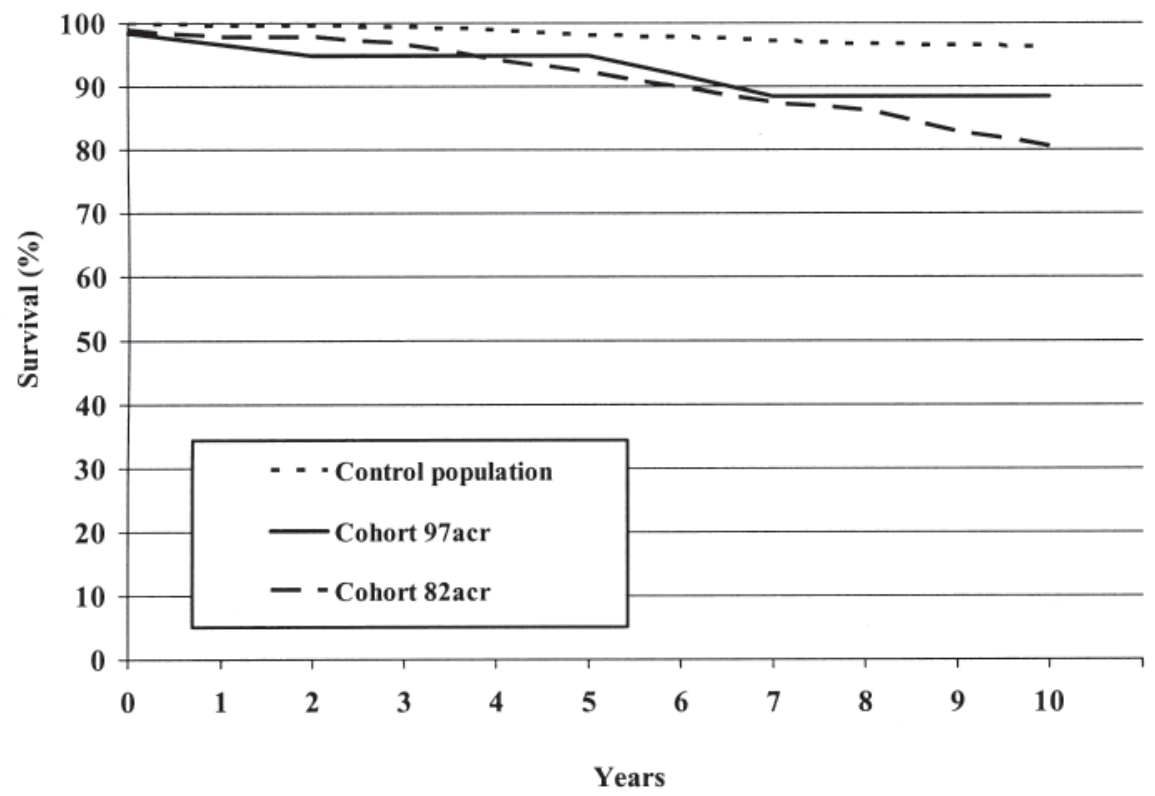

Figure 2. Survival among SLE patients in cohort 97acr (diagnosed by ACR97), cohort 82acr (diagnosed by ACR82), and control population. For cohort 97acr and controls $\mathrm{p}=0.004$ and for cohort 82 acr and controls $\mathrm{p}<0.001$, by log-rank test.

Table 4. Predictors for mortality in SLE within 10 years after diagnosis, by univariate analysis (hazard ratio, both cohorts) and multivariate analysis (adjusted HR, cohort 82acr only). Clinical criteria reflect findings at scientific diagnosis, drug treatment during the first 4 months after diagnosis, SLICC/ACR DI $>0$ one year after diagnosis, hypocomplementemia during first year of disease; and ever-positive test for aPL antibodies.

\begin{tabular}{|c|c|c|c|c|c|c|c|c|c|c|}
\hline Criteria & $\begin{array}{c}\text { Died, } \\
\mathrm{n}=5(\%)\end{array}$ & $\begin{array}{c}\text { Alive, } \\
\mathrm{n}=57(\%)\end{array}$ & HR & $95 \% \mathrm{CI}$ & $\begin{array}{c}\text { Died, } \\
\mathrm{n}=17(\%)\end{array}$ & $\begin{array}{c}\text { Alive, } \\
\mathrm{n}=70(\%)\end{array}$ & HR & $95 \% \mathrm{CI}$ & $\begin{array}{c}\text { Adjusted } \\
\text { HR }\end{array}$ & $95 \% \mathrm{CI}$ \\
\hline Malar rash & $2(40)$ & $35(61)$ & 0.4 & $0.1-2.6$ & $6(35)$ & $43(61)$ & 0.4 & $0.1-0.9$ & 0.8 & $0.2-2.4$ \\
\hline Photosensitivity & $2(40)$ & $30(53)$ & 0.5 & $0.1-3.2$ & $8(47)$ & $48(69)$ & 0.4 & $0.2-1.1$ & & \\
\hline Oral ulcers & 0 & $21(21)$ & 0.04 & $0.0-651$ & $2(12)$ & $26(37)$ & 0.2 & $0.1-1.0$ & & \\
\hline Methylprednisolone & $2(40)$ & $4(7)$ & 1.5 & $1.1-2.0$ & 0 & $3(4)$ & 0.6 & $0.1-3.6$ & & \\
\hline Cyclophosphamide & $2(40)$ & $4(7)$ & 5.2 & $0.9-31$ & $1(6)$ & $11(16)$ & 0.3 & $0.0-2.5$ & & \\
\hline Low-dose aspirin & $4(80)$ & $8(14)$ & 1.3 & $1.1-1.5$ & 0 & 0 & & & & \\
\hline Antihypertensives & $3(60)$ & $1(2)$ & 1.3 & $1.1-1.4$ & 0 & $2(3)$ & & & & \\
\hline SLICC/ACR DI $>0$ & $2(40)$ & $17(30)$ & 1.4 & $0.2-8.1$ & $5(29)$ & $7(10)$ & 2.8 & $1.0-8.0$ & 1.7 & $0.6-5.0$ \\
\hline Low C3 & $3(60)$ & $11(19)$ & 5.4 & $0.9-32$ & $6(35)$ & $31(44)$ & 0.7 & $0.3-1.9$ & & \\
\hline
\end{tabular}

NSAID: nonsteroidal antiinflammatory drugs; SLICC/ACR DI: Systemic Lupus International Collaborating Clinics/ACR Damage Index; aPL: antiphospholipid antibodies.

\section{DISCUSSION}

In an effort to determine the validity of the 1997 update of the ACR classification criteria for SLE, a longterm population-based study of SLE was performed. The use of the ACR97 criteria did not lead to changes in SLE incidence or demographics, as all patients fulfilled the ACR82 criteria as well. However, the clinical disease pattern did change over time, with a significant reduction in the frequency of renal disease and increased use of assays for lower avidity ds-
DNA and aPL antibody as classification criteria. Concurrent increased use of early treatment with pulse methylprednisolone, azathioprine, and low-dose aspirin and more intense serological surveillance may have further contributed to this "prevention" of renal disease with subsequent improvements in overall 5- and 10-year survival rates for the whole cohort.

The negligible increase in SLE incidence during the last decade is in accord with earlier observations from southern 
Sweden ${ }^{10}$. The average AIR (3.0 per 100,000 adults) remains within the range of reported Scandinavian incidence rates $(1.5-4.8 \text { per } 100,000)^{3,5,6,10,23}$. Studies from other regions give conflicting data. In the French West Indies no changes in SLE incidence have occurred ${ }^{24}$, while the Mayo Clinic in Rochester, MN, USA, describes a tripling of SLE incidence in the period 1950-92 ${ }^{9}$. The Rochester population has a strong Nordic background and the overall incidence rate for the study was $3.0 / 100,000^{9}$, similar to our data, so the increase observed in Rochester may be a catchup effect. The trend towards increasing AIR in women for the 30-49 age group (8.3) is in line with other studies $^{5,6,25}$, however, aside from the high AIR (14.1) seen in women 65-74 years old in southern Sweden ${ }^{10}$. SLE prevalence in Northern Norway was highest in postmenopausal women $(1.3$ per 1,000$)$, making SLE a disease currently seen in 1 per 770 women in this age group. The increasing overall prevalence (64.1 per 100,000 as of January 1,2007) is due to a stable disease incidence and improved survival.

While not a primary aim of our study, we observed a stable incidence and no case fatalities in children with SLE in northern Norway. The mean AIR was 0.9 per 100,000 for children, somewhat higher compared with other studies on Scandinavian cohorts ${ }^{23,26}$.

Despite few changes in epidemiological characteristics, remarkable changes in the clinical presentation of SLE over time occurred. The average number of classification criteria at diagnosis decreased significantly, even though the time from the first symptom attributable to SLE was 1 year in both cohorts. Increased reliance on sensitive, although not necessarily specific, autoantibody assays for anti-dsDNA and aPL seems to have become an essential part of the diagnostic investigation and classification process. The fact that overall disease activity at diagnosis was similar is not in contradiction with this, as the SLEDAI incorporates several recognized disease manifestations not covered by the classification criteria (e.g., alopecia, vasculitis, cerebrovascular accidents, fever, and hypocomplementemia). These data thus imply that, currently, physicians with the use of sensitive assays recognize SLE at an earlier stage before severe and/or multi-organ presentation develops and also include serological surveillance more often in patient management ${ }^{27}$.

The decrease in the number of patients with lupus nephritis in the 97acr cohort in our study is especially intriguing. Most studies link lupus nephritis to the presence of nephritogenic high avidity anti-dsDNA Ab as detected by $C$. luciliae immunofluorescence or the Farr radioactivity assay ${ }^{28-30}$. Anti-dsDNA Ab are, however, often present long before SLE is clinically apparent and they gradually obtain their nephritogenic potential through repeated antigenic stimulation $^{28,31,32}$. Several short-term prospective studies have shown that intensive anti-dsDNA Ab surveillance can help prevent disease flares such as lupus nephritis ${ }^{33,34}$. In our study the 97 acr cohort was surveyed more frequently for early serological disease markers, had increased early treatment with pulse steroids and azathioprine, and generally had milder lupus. Altogether this may lend support to the accumulated theory on lupus development. While our observational data only provide circumstantial evidence, they at least support the idea that severe lupus could be prevented by intervening in the mechanism behind the antibody maturation response and thereby reducing the risk of renal disease and attaining the goal of milder lupus.

It is, however, important to note that established renal disease remained a strong risk factor for reduced short-term survival (HR 10.9) ${ }^{35-37}$. Therefore, lupus nephritis remains a potentially severe, although now less frequent, complication of SLE in Caucasian patients, and the use of serological surveillance in the prevention of lupus nephritis deserves further study.

A similar case can be made for increased surveillance for aPL antibodies. aPL screening was reinforced by the ACR97 criteria, and aPL Ab are detectable in the serum of patients with SLE many years before diagnosis and prior even to anti-dsDNA $\mathrm{Ab}^{32,38}$. While the pathogenic characteristics of aPL are less well defined than for anti-dsDNA Ab, increased serological surveillance likely contributed to earlier identification of cases in the 97acr cohort, and clearly contributed to patient management measures as illustrated by the preventive treatment with low-dose aspirin in $21 \%$ of newly diagnosed patients ${ }^{39}$.

Patients with SLE in northern Norway remain at risk of premature death, as indicated by the overall SMR of 2.00 for the whole study period. During the 1970s and 1990s, SMR for lupus cohorts ranged between 2.7 and 4.9 around the world ${ }^{40-42}$. Some studies from the last decade report decreasing SMR, with a study from Greece reporting a SMR of only $1.5^{36,43}$. In our study, SMR was higher in cohort 97acr (3.00) than in cohort 82acr (1.88). Mortality in SLE has been described as having a bimodal pattern, with an early mortality peak mainly due to active disease and a later peak associated to cardiovascular complications ${ }^{44,45}$. Given the disease duration of only 19 months at death in the $97 \mathrm{acr}$ cohort, this increased SMR can likely represent the first peak in the mortality curve. Alternatively, the increased SMR may reflect a larger reduction in mortality in the control group than in the SLE cohort due to improved general healthcare delivery and living standards. For the whole period, SMR was highest in women under 30 years of age and lowest in the elderly, similar to data from various other cohorts $^{36,40,41}$.

Both 5- and 10-year survival rates were improved for the 97 acr cohort compared with 82acr cohort, in line with other single-center studies ${ }^{10,46}$. This development naturally reflects the combined effects of earlier case recognition with subsequent inclusion of patients with milder form of dis- 
ease, advances in therapeutic modalities, and more judicious use of existing therapies such as hydroxychloroquine ${ }^{47}$. Cardiovascular disease is an increasingly important contributor to SLE mortality, and together with infections is the most frequent cause of death ${ }^{19,41,48}$; and while low numbers did not allow detailed analyses, causes of death in cohort 97acr were also mainly cardiovascular (40\%) and infectious (40\%), with 1 patient in a fatal accident (20\%).

Of necessity, our study is observational and we are aware of the biases incurred by such study design and the relatively low number of patients. While the use of an earlier-inception cohort, the single-center setting, and the long followup time provided some measure of control, selection bias may nonetheless have influenced our conclusions, which will need further confirmation. The differences in observation times precluded any firm conclusions on mortality differences between the 2 cohorts, while low numbers did not allow us to perform statistically meaningful analyses of specific causes of death.

The ACR97 criteria set was found to have excellent construct validity compared to the ACR82 criteria. While the incidence of SLE in northern Norway remained constant between 1978 and 2006, an increase in the use of serological classification criteria coincided with a notable reduction in prevalence of lupus nephritis. The increased use of a sensitive ELISA for anti-dsDNA and aPL antibodies may thus have allowed earlier identification of patients at risk for severe disease. Together with a more aggressive therapeutic approach, this seems to have contributed to milder lupus in a number of patients, with subsequent improvements in survival.

\section{ACKNOWLEDGMENT}

We thank Dr. G. Myklebust, Sørlandet Hospital HF Kristiansand, Norway, for critical reading and valuable advice.

\section{REFERENCES}

1. Jacobson DL, Gange SJ, Rose NR, Graham NM. Epidemiology and estimated population burden of selected autoimmune diseases in the United States. Clin Immunol Immunopathol 1997;84:223-43.

2. Klippel JH. Systemic lupus erythematosus: demographics, prognosis, and outcome. J Rheumatol 1997;24 Suppl 48:67-71.

3. Gudmundsson S, Steinsson K. Systemic lupus erythematosus in Iceland 1975 through 1984. A nationwide epidemiological study in an unselected population. J Rheumatol 1990;17:1162-7.

4. Johnson AE, Gordon C, Palmer RG, Bacon PA. The prevalence and incidence of systemic lupus erythematosus in Birmingham, England. Relationship to ethnicity and country of birth. Arthritis Rheum 1995;38:551-8.

5. Nossent HC. Systemic lupus erythematosus in the Arctic region of Norway. J Rheumatol 2001;28:539-46.

6. Voss A, Green A, Junker P. Systemic lupus erythematosus in Denmark: clinical and epidemiological characterization of a county-based cohort. Scand J Rheumatol 1998;27:98-105.

7. Borchers AT, Keen CL, Shoenfeld Y, Gershwin ME. Surviving the butterfly and the wolf: mortality trends in systemic lupus erythematosus. Autoimmun Rev 2004;3:423-53.

8. Hochberg MC. The incidence of systemic lupus erythematosus in Baltimore, Maryland, 1970-1977. Arthritis Rheum 1985;28:80-6.
9. Uramoto KM, Michet CJ Jr, Thumboo J, Sunku J, O'Fallon WM, Gabriel SE. Trends in the incidence and mortality of systemic lupus erythematosus, 1950-1992. Arthritis Rheum 1999;42:46-50.

10. Stahl-Hallengren C, Jonsen A, Nived O, Sturfelt G. Incidence studies of systemic lupus erythematosus in Southern Sweden: increasing age, decreasing frequency of renal manifestations and good prognosis. J Rheumatol 2000;27:685-91.

11. Tan EM, Cohen AS, Fries JF, et al. The 1982 revised criteria for the classification of systemic lupus erythematosus. Arthritis Rheum 1982;25:1271-7.

12. Hochberg MC. Updating the American College of Rheumatology revised criteria for the classification of systemic lupus erythematosus [letter]. Arthritis Rheum 1997;40:1725.

13. Avcin T, Toplak N. Antiphospholipid antibodies in response to infection. Curr Rheumatol Rep 2007;9:212-8.

14. Gomez-Puerta JA, Cervera R, Espinosa G, et al. Antiphospholipid antibodies associated with malignancies: clinical and pathological characteristics of 120 patients. Semin Arthritis Rheum 2006;35:322-32.

15. Miyakis $\mathrm{S}$, Lockshin MD, Atsumi T, et al. International consensus statement on an update of the classification criteria for definite antiphospholipid syndrome (APS). J Thromb Haemost 2006;4:295-306.

16. Vaarala $\mathrm{O}$, Manttari M, Manninen V, et al. Anti-cardiolipin antibodies and risk of myocardial infarction in a prospective cohort of middle-aged men. Circulation 1995;91:23-7.

17. Koike T, Bohgaki M, Amengual O, Atsumi T. Antiphospholipid antibodies: lessons from the bench. J Autoimmun 2007;28:129-33.

18. Merrell M, Shulman LE. Determination of prognosis in chronic disease, illustrated by systemic lupus erythematosus. J Chronic Dis 1955;1:12-32.

19. Nossent J, Cikes N, Kiss E, et al. Current causes of death in systemic lupus erythematosus in Europe, 2000-2004: relation to disease activity and damage accrual. Lupus 2007;16:309-17.

20. Arce-Salinas A, Cardiel MH, Guzman J, Alcocer-Varela J. Validity of retrospective disease activity assessment in systemic lupus erythematosus. J Rheumatol 1996;23:846-9.

21. Bernatsky S, Clarke A, Abrahamowicz M, Neville C, Karp I, Pineau CA. A comparison of prospective and retrospective evaluations of the Systemic Lupus International Collaborating Clinics/American College of Rheumatology Damage Index for systemic lupus erythematosus. J Rheumatol 2005;32:820-3.

22. Brandt JT, Triplett DA, Alving B, Scharrer I. Criteria for the diagnosis of lupus anticoagulants: an update. On behalf of the Subcommittee on Lupus Anticoagulant/Antiphospholipid Antibody of the Scientific and Standardisation Committee of the ISTH. Thromb Haemost 1995;74:1185-90.

23. Jonsson H, Nived O, Sturfelt G, Silman A. Estimating the incidence of systemic lupus erythematosus in a defined population using multiple sources of retrieval. Br J Rheumatol 1990;29:185-8.

24. Deligny C, Thomas L, Dubreuil F, et al. [Systemic lupus erythematosus in Martinique: an epidemiologic study]. Rev Med Interne 2002;23:21-9.

25. Michet CJ Jr, McKenna CH, Elveback LR, Kaslow RA, Kurland LT. Epidemiology of systemic lupus erythematosus and other connective tissue diseases in Rochester, Minnesota, 1950 through 1979. Mayo Clin Proc 1985;60:105-13.

26. Pelkonen PM, Jalanko HJ, Lantto RK, et al. Incidence of systemic connective tissue diseases in children: a nationwide prospective study in Finland. J Rheumatol 1994;21:2143-6.

27. Nossent H, Rekvig OP. Antinuclear antibody screening in this new millennium: farewell to the microscope? Scand J Rheumatol 2001;30:123-6.

28. Haugbro K, Nossent JC, Winkler T, Figenschau Y, Rekvig OP. Anti-dsDNA antibodies and disease classification in antinuclear 
antibody positive patients: the role of analytical diversity. Ann Rheum Dis 2004;63:386-94.

29. Neogi T, Gladman DD, Ibanez D, Urowitz M. Anti-dsDNA antibody testing by Farr and ELISA techniques is not equivalent. J Rheumatol 2006;33:1785-8.

30. Riboldi P, Gerosa M, Moroni G, et al. Anti-DNA antibodies: a diagnostic and prognostic tool for systemic lupus erythematosus? Autoimmunity 2005;38:39-45.

31. Rekvig OP, Nossent JC. Anti-double-stranded DNA antibodies, nucleosomes, and systemic lupus erythematosus: a time for new paradigms? Arthritis Rheum 2003;48:300-12.

32. Arbuckle MR, McClain MT, Rubertone MV, et al. Development of autoantibodies before the clinical onset of systemic lupus erythematosus. N Engl J Med 2003;349:1526-33.

33. Alarcon-Segovia D, Tumlin JA, Furie RA, et al. LJP 394 for the prevention of renal flare in patients with systemic lupus erythematosus: results from a randomized, double-blind, placebo-controlled study. Arthritis Rheum 2003;48:442-54.

34. Bootsma H, Spronk P, Derksen R, et al. Prevention of relapses in systemic lupus erythematosus. Lancet 1995;345:1595-9.

35. Abu-Shakra M, Urowitz MB, Gladman DD, Gough J. Mortality studies in systemic lupus erythematosus. Results from a single center. II. Predictor variables for mortality. J Rheumatol 1995;22:1265-70

36. Bernatsky S, Boivin JF, Joseph L, et al. Mortality in systemic lupus erythematosus. Arthritis Rheum 2006;54:2550-7.

37. Kasitanon N, Magder LS, Petri M. Predictors of survival in systemic lupus erythematosus. Medicine (Baltimore) 2006;85:147-56.

38. McClain MT, Arbuckle MR, Heinlen LD, et al. The prevalence, onset, and clinical significance of antiphospholipid antibodies prior to diagnosis of systemic lupus erythematosus. Arthritis Rheum 2004;50:1226-32.
39. Hereng T, Lambert M, Hachulla E, et al. Influence of aspirin on the clinical outcomes of 103 anti-phospholipid antibodies-positive patients. Lupus 2008;17:11-5.

40. Abu-Shakra M, Urowitz MB, Gladman DD, Gough J. Mortality studies in systemic lupus erythematosus. Results from a single center. I. Causes of death. J Rheumatol 1995;22:1259-64.

41. Bjornadal L, Lofstrom B, Yin L, Lundberg IE, Ekbom A. Increased cancer incidence in a Swedish cohort of patients with systemic lupus erythematosus. Scand J Rheumatol 2002;31:66-71.

42. Manger K, Manger B, Repp R, et al. Definition of risk factors for death, end stage renal disease, and thromboembolic events in a monocentric cohort of 338 patients with systemic lupus erythematosus. Ann Rheum Dis 2002;61:1065-70.

43. Alamanos Y, Voulgari PV, Papassava M, Tsamandouraki K, Drosos AA. Survival and mortality rates of systemic lupus erythematosus patients in northwest Greece. Study of a 21-year incidence cohort. Rheumatology Oxford 2003;42:1122-3.

44. Ward MM, Pyun E, Studenski S. Causes of death in systemic lupus erythematosus. Long-term followup of an inception cohort. Arthritis Rheum 1995;38:1492-9.

45. Urowitz MB, Bookman AA, Koehler BE, Gordon DA, Smythe HA, Ogryzlo MA. The bimodal mortality pattern of systemic lupus erythematosus. Am J Med 1976;60:221-5.

46. Urowitz MB, Gladman DD, Abu-Shakra M, Farewell VT. Mortality studies in systemic lupus erythematosus. Results from a single center. III. Improved survival over 24 years. J Rheumatol 1997;24:1061-5.

47. Abu-Shakra M, Gladman DD, Urowitz MB. Mortality studies in SLE: how far can we improve survival of patients with SLE. Autoimmun Rev 2004;3:418-20.

48. Manzi S, Meilahn EN, Rairie JE, et al. Age-specific incidence rates of myocardial infarction and angina in women with systemic lupus erythematosus: comparison with the Framingham Study. Am J Epidemiol 1997;145:408-15. 